\title{
Supraglottic Laryngeal Paraganglioma: A Rare Clinical Entity managed by Lateral Pharyngotomy Approach
}

\section{Sudhir M Naik}

\section{ABSTRACT}

Background/objectives: Laryngeal paragangliomas are benign slow growing tumors with symptoms resembling squamous cell carcinoma. Hoarseness or dysphasia is the commonest presenting symptom and usually it presents as a submucosal mass on laryngoscopy. A total of $90 \%$ of these tumors occur in the supraglottic larynx and the rest in the glottis and the subglottic region. Functional activity is seen in a few (2.9\%), none are associated with paraneoplastic syndromes.

Setting: Department of Head and Neck Oncosurgery, Kidwai Memorial Institute of O ncology, Bengaluru.

Case report: A 35-year-old male presented to us with hoarseness of voice since 4 months duration. Contrast arteriography demonstrated that the left superior thyroid artery supplied greater than $80 \%$ of the blood supply to the laryngeal mass. Superselective embolization was done from the right femoral under local anesthesia and sedation which was uneventful.

Intervention: The tumor was excised from lateral pharyngotomy approach with an elective tracheostomy. Microscopy suggested it to be paraganglioma and immunohistochemistry confirmed it.

Conclusion: Complete surgical resection or partial laryngectomy with meticulous dissection of surrounding tissues and preservation of neurovascular structures give an excellent prognosis as far as oncological clearance is concerned. Malignant paragangliomas of the larynx are rare and a major meta-analysis is necessary to provide a true biological behavior of this tumor.

Keywords: Paraganglioma, Embolization, Lateral pharyngotomy, Digital subtraction angiography.

How to cite this article: Naik SM. Supraglottic Laryngeal Paraganglioma: A Rare Clinical Entity managed by Lateral Pharyngotomy Approach. Int J Phonosurg Laryngol 2012;2(2): 69-73.

\section{Source of support $\mathrm{Nil}$}

Conflict of interest: None declared

\section{INTRODUCTION}

Head and neck paragangliomas are rare tumors arising from the neural crest. ${ }^{1,2}$ They are highly vascularized tumors involving the walls of the blood vessels or specific nerves. ${ }^{3-5}$ In the larynx, they arise from superior or inferior laryngeal paraganglia and are seen in the supraglottis in $90 \%$ of the cases. ${ }^{6}$ Since these tumors are from neural crest-derived cells of the parasympathetic nervous system, they usually appear adjacent to nerve structures, most commonly the superior laryngeal nerve or the recurrent laryngeal nerve. ${ }^{7}$
The paragangliomas of the larynx show a female preponderance compared to other neuroendocrine tumors. ${ }^{6}$ Other neuroendocrine tumors differ in their biologic behavior, management and prognosis compared to paragangliomas and so immunohistochemical differentiation forms an important criteria. ${ }^{8}$ Paragangliomas of larynx are benign submucosal lesion and the management includes a conservative resection. ${ }^{6}$ Significant intraoperative blood loss is expected so preoperative transarterial embolization has proved beneficial. ${ }^{9,10}$ Percutaneous direct intratumoral embolization can also be done with same efficacy. ${ }^{11-14}$ Supraglottic laryngectomy and lateral pharyngotomy are commonly used approaches for managing these paragangliomas. ${ }^{15-20}$

\section{CASE REPORT}

A 35-year-old male presented to us with hoarseness of voice since 4 months duration. There was no history of difficulty in swallowing and any other symptoms. Also on examination, a swelling in left side of the neck was seen confirmed on pal pation. Indirect laryngoscopic examination reveal ed a congested globular flashy mass arising from the left pharyngoepiglottic fold, extending to the aryepiglottic fold and to the apex of the pyriform fossa with mobile vocal cords.

The patient was a nonsmoker and nondrinker also; complained of foreign body sensation. Contrast-enhanced computed tomographic (CT) scan was done and an enhancing lesion was seen in the same region with radiological features suggesting of a vascular lesion or a paraganglioma (Fig. 1). Translaryngeal fine needle
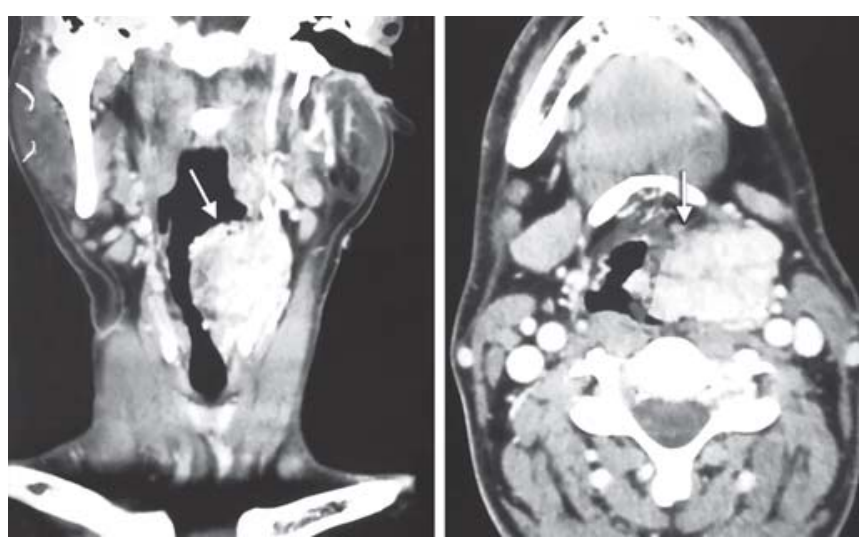

Fig. 1: Contrast-enhanced CT images showing the left supraglottic tumor 
aspiration cytology revealed cells similar to that of paraganglioma, but a vascular malformation and schwannomas were not ruled out. His blood investigations and urine catecholamine levels were normal. Magnetic resonance angiography revealed a 3 to $4 \mathrm{~cm}$ vascular lesion in the left supraglottic region but the feeder vessels were not found. So, a digital subtraction angiography (DSA) done revealed the superior thyroid artery to be the feeder and a minor contribution from contralateral superior thyroid was seen.

DSA demonstrated that the left superior thyroid artery supplied greater than $80 \%$ of the blood supply to the laryngeal mass (Fig. 2). Superselective embolization was done from the right femoral under local anesthesia and sedation which was uneventful. L eft superior thyroid artery was selectively catheterized using the $4 \mathrm{~F}$ vertebral glide catheter over the 0.035 Terumo guide wire and embolized using 510 to 750 sized polyvinyl alcohol (PVA) particles. A minimal tumor blush was noted after this and the feeders were embolized using a microguide wire with 250 to 500 PVA particles. Finally, after embolization, partial tumor blush was seen with feeders from the proximal part of the left superior thyroid artery. Since these feeders were close to origin of external carotid artery, no attempt was made to block these feeders. There was no other neurological deficit noticed after embolization.

Direct laryngoscopic evaluation was done in 48 hours and the pulsatile vascular lesion was assessed and approached from a lateral pharyngotomy incision. A $n$ elective tracheostomy was done to secure the patient's airway before lateral pharyngotomy with minimal blood loss. Intraoperatively, the larynx was approached and the thyroid ala dissected and left superior thyroid artery was ligated and cut al ong with the superior laryngeal nerve. The subglottis was normal, as was the base of the tongue and pharynx (Fig. 3).
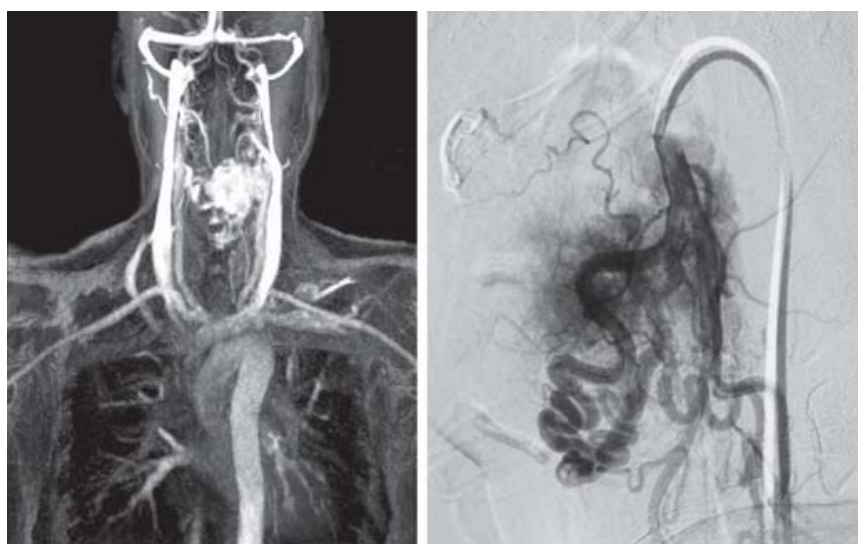

Fig. 2: MRI angiography and DSA showing embolization

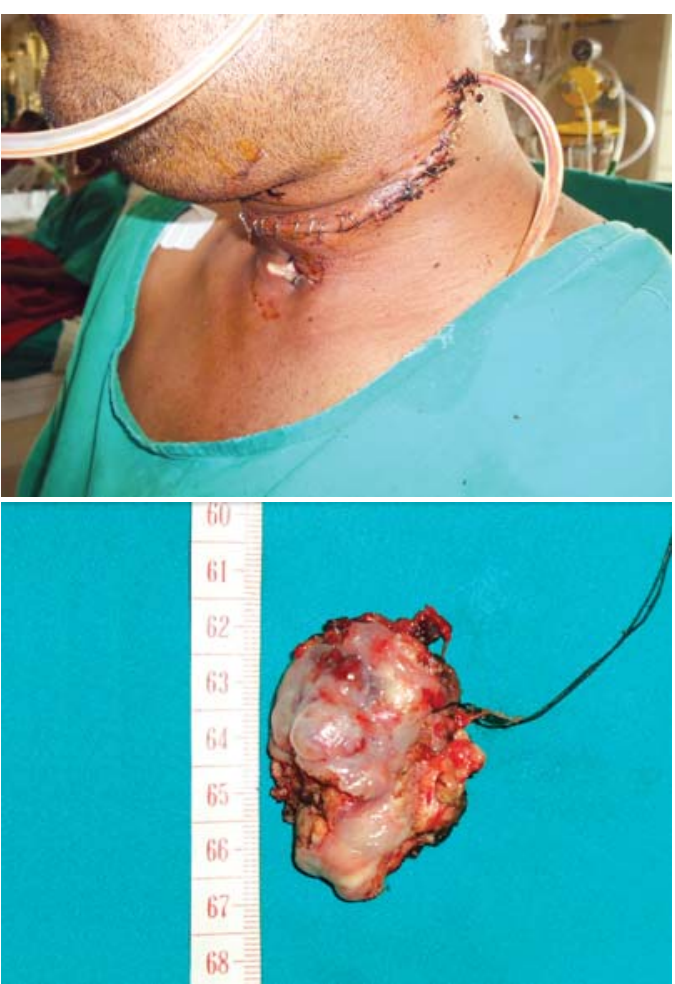

Fig. 3: Lateral pharyngotomy approach with the tumor specimen

L ater the thyroid cartilage was dissected and the tumor was excised. Hewas extubated with the postoperative period being uneventful. Histopathology revealed features suggestive of paraganglioma and all the lymph nodes had reactive changes. Microscopic examination showed polygonal epithelioid cells arranged in discrete nests (Zell ballen pattern). Immunohistochemistry results show ed that the neoplastic cells were positive for chromogranin, synaptophysin and S-100 but negative for CK and epithelial membrane antigen (EMA). So, all these features were consistent with paraganglioma.

\section{DISCUSSION}

Laryngeal paraganglioma was first described in 1955 and since then 85 cases were described in world literature. ${ }^{8}$ Ferlito et al analyzed all the reported paragangliomas of the larynx and found that 62 case reports genuinely met the criteria for diagnosis. ${ }^{2,8,16}$

These are benign slow growing tumors with symptoms resembling squamous cell carcinoma. ${ }^{8}$ Hoarseness or dysphasia are the commonest presenting symptoms and usually it presents as a submucosal mass on laryngoscopy. ${ }^{8}$ Rarely stridor, dysphagia, foreign body sensation and dyspnea are seen and depends on the size and location of the tumor. ${ }^{16}$ The majority of these tumors arise in the supraglottic larynx, and $2 \%$ of these are malignant. 2,8,16

A histological diagnosis is necessary prior to surgical treatment and repetitive fine needle aspiration biopsies are 
Supraglottic Laryngeal Paraganglioma: A Rare Clinical Entity managed by Lateral Pharyngotomy Approach

advised, if they are inconclusive. ${ }^{5}$ Superficial biopsies are inconclusive as they have intact mucosa, but deeper biopsies can complicate as these lesions are highly vascular. ${ }^{21}$ Translaryngeal biopsies are helpful in these conditions as done in our case.

Laryngeal paragangliomas have the same appearance as paragangliomas of other sites on histopathology. ${ }^{22}$ They are highly vascular and composed of chief cells and sustentacular cells, arranged in a characteristic alveolar or Zellballen pattern. ${ }^{22}$ The chief cells (type I cells, epithelioid cells) are more numerous and contain catecholamine bound neurosecretory granules and the sustentacular cells (type II cells, supporting cells) are devoid of neurosecretory granules and are characteristically located at the periphery of Zellballen. ${ }^{2}$ Zellballen pattern are also seen in typical and atypical carcinoid, malignant melanoma and medullary carcinoma of thyroid and are not specific for paragangliomas. ${ }^{22}$

Differentiating laryngeal paragangliomas from carcinoids, atypical carcinoids and other neuroendocrine carcinoma on microscopic examination is not impossible and immunohistochemistry is helpful. ${ }^{22}$ The chief cells are immunoreactive to neuroendocrine markers chromogranin, synaptophysin and neuron-specific enolase and negative for epithelial markers including cytokeratin. ${ }^{1,20}$ A typical carcinoids of the larynx show immunoreactivity for both neuroendocrine markers and epithelial markers. ${ }^{6}$

The sustentacular cells are immunoreactive to S-100, but chief cells are negative for melanoma markers S-100, HM B 45 and melan-A, excluding this from melanoma. ${ }^{23}$ Non-neuroendocrine tumors are excluded by chromogranin positivity and the absence of keratin positivity and presence of S-100 protein-positive sustentacular cells tends to exclude carcinomas. ${ }^{24}$ These tumors can be confused on microscopy as carcinoid tumor, malignant melanoma, medullary thyroid carcinoma and small-cell neuroendocrine carcinoma. ${ }^{24}$

S-100 testing is particularly necessary to establish the correct diagnosis as its negative in typical and atypical carcinoid and small-cell neuroendocrine carcinoma. ${ }^{25}$ Cytokeratin, epithelial membrane antigen, carcinoembryonic antigen are negative in paragangliomas while positive in carcinoids and small-cell neuroendocrine carcinoma. ${ }^{25}$ Chromogranin, synaptophysin, neuronspecific enolase are positive in all the laryngeal neuroendocrine tumors. ${ }^{25} \mathrm{G}$ alanin, glial fibrillary acidic protein are very specific for laryngeal paragangliomas. ${ }^{25}$

The mutations in the SHDB, SDHC and SHDD genes reflect higher risk for developing malignant paragangliomas, whereas VHL and NF1 genes mutation reflect inherited paragangliomas. ${ }^{26,27}$ Rare cases of laryngeal paraganglioma associated with multicentric head and neck paraganglioma syndrome are also reported. ${ }^{28}$

A total of $90 \%$ of these tumors occur in the supraglottic larynx and the rest in the glottis and the subglottic region. Functional activity is seen in a few $(2.9 \%)$, none are associated with paraneoplastic syndromes. ${ }^{1,19}$ They spread by vocal fold fixation and rarely associated with necrosis and vascular invasion. ${ }^{1,19}$ Some herniate through the thyrohyoid membrane and present as a neck mass. ${ }^{29}$ If imaging provide sufficient evidence of probable diagnosis of paraganglioma (or any other vascular tumor), then a biopsy can be omitted and direct surgery following angiography and embolization seems better. ${ }^{5}$ Some tumors may be large enough to herniate through the thyrohyoid membrane and present as a neck mass. ${ }^{11}$

Contrast-enhanced computerized tomography (CECT neck) and contrast-enhanced magnetic resonance imaging (M RI) rules out less enhancing laryngeal masses..$^{15} \mathrm{MRI}$ is also useful in detecting lesions that are smaller than $5 \mathrm{~mm}$ and to screen for synchronous paragangliomas. ${ }^{30,31}$ Contrast-enhanced MRI angiography (MRA) does not increase the diagnostic value of $M R I$ but defines the vascularity of the tumor. ${ }^{32}$

DSA is more sensitive in detecting vascularization compared to M RA..$^{10,33} \mathrm{~A}$ I so tumors larger than $2.5 \mathrm{~cm}$, four vessel angiography and preoperative embolization is useful in minimizing bleeding and injury to surrounding neurovascular structures. ${ }^{10,33}$ DSA also allows the determination of carotid artery invasion and the performance of balloon occlusion studies to assess collateral cerebral circulation in carotid body paragangliomas. ${ }^{10,33}$

U sually superior thyroid artery is the primary vessel that supplies these tumors, so embolization creates a bloodless surgical field. ${ }^{34}$ Preoperative embolization done by superselective catheterization of the supplying branches and transarterial embolization with particulate agents dramatically improves the operative field. ${ }^{35}$

Sonography-guided or CT-guided intratumoral injection of a liquid adhesive like N-butyl-2-cyanoacrylate (N BCA ) gives better devascularization compared to transarterial embolization and is a safe and effective method of preoperative embolization. ${ }^{11-14}$

Percutaneous direct embolization provides an easy access to hypervascular tumor with a higher chance of achieving complete devascularization. ${ }^{12,36}$ Direct embolization is typically carried out with NBCA. ${ }^{12,36}$ Percutaneous tumor embolization is easy and safe but complications of glue migration into the intracranial circulation is a fatal complication. ${ }^{12,36}$ Casasco et al advocated the use of nondetachable balloons to protect the 
intracranial branches to reduce the risk of glue reflux into the circulation. ${ }^{12,36} \mathrm{~N}$ o other complications are reported in the procedure. ${ }^{12,36}$

M ost of the laryngeal paragangliomas are managed surgically and organ preservation partial laryngectomy procedures are becoming the standard protocol. ${ }^{1,6}$ Radical surgeries are not indicated as regional and distant metastasis are rarely documented. ${ }^{1,6}$ Transoral resections are not advised because hemostasis management can prove fatal, so lateral pharyngotomy is preferred depending on the extent and site of the tumor. ${ }^{1,6}$ The endoscopic approach provides limited exposure and access to the lesion. ${ }^{6}$ This is not a good approach for vascular tumors, because hemorrhage might obscure visualization of tissue planes. ${ }^{6}$ The biological behavior of the tumor is not extensively defined as the tumor is rare and the malignant potential hardly exist. ${ }^{37} \mathrm{~A} / \mathrm{l}$ these lesions are treated by surgical resection which includes supraglottic or total laryngectomy and endoscopic resection. ${ }^{18,37}$ Inferior laryngeal paragangliomas present in the subglottis having dyspnea and shortness of breath and need careful consideration for airway management preoperatively. ${ }^{18,37}$ M ost of them were managed by total laryngectomy as the primary treatment. 18,37

L ateral pharyngotomy approach is described for removal of supraglottic submucosal tumors, including paraganglioma. ${ }^{17}$ All procedures are aimed at complete tumor removal with minimum functional deficits. ${ }^{17} \mathrm{~T}$ his approach can be performed without a tracheostomy for smaller lesions, but for resection of vascular masses, a tracheotomy should be performed. ${ }^{6} \mathrm{~A}$ Iso conservation laryngeal approaches are not attempted when cartilage involvement is seen radiographically. ${ }^{18,37}$ Submucosal resection with meticulous dissection results in no postoperative dysphagia and excellent voice preservation. ${ }^{6}$

Laryngeal paragangliomas are benign tumors and presence of vascular, capsular or perineural invasion, focal necrosis, mitoses does not indicate metastatic potential. ${ }^{38,39}$

$M$ alignant paragangliomas are reported in $2 \%$ in some series, while pathologic findings cannot predict clinical and biological behavior of the tumor. ${ }^{1,2,34} \mathrm{R}$ are cases of distant metastasis are reported, while neck nodes spread are rarely reported and so selective neck node clearance is not warranted. ${ }^{1,2}$ Regular follow-up is advised as not much literature on the biological behavior of the tumor is known. ${ }^{38,39} \mathrm{~A}$ recurrence rates of $17 \%$ is reported in superior laryngeal paragangliomas and $4 \%$ in inferior laryngeal paraganglioma with careful follow-up should be given to the inferior laryngeal cases due to the potential for rapid airway obstruction with recurrent or persistent disease. ${ }^{18,37}$ L ocal recurrence may be a sign of malignancy. ${ }^{18,37}$
No role of radiotherapy or chemotherapy is used as a laryngeal preservation approach. ${ }^{5}$ In cervical paragangliomas, external beam radiation provides approximately $90 \%$ tumor control rate. ${ }^{5}$

Ferlito et al suggested the existence of other atypical carcinoid tumors as high as $25 \%$ which were earlier thought as metastasis. ${ }^{1,2,34}$ They reviewed 65 cases over 35 years and found the mean age to be 44 years, mean duration of symptoms to be 26 months and most of the tumors were excised surgically. ${ }^{1,2,34}$ They reported no role of radiation or chemotherapy. ${ }^{5}$

\section{CONCLUSION}

Early diagnosis of these laryngeal paragangliomas is difficult as they present with nonspecific clinical manifestation. Complete surgical resection or partial laryngectomy with meticulous dissection of surrounding tissues and preservation of neurovascular structures gives an excellent prognosis as far as oncological clearance is concerned. M alignant paragangliomas of the larynx are rare and a major meta-analysis is necessary to provide a true biological behavior of this tumor.

\section{REFERENCES}

1. Ferlito A, Barnes L, Rinaldo A, Gnepp DR, M ilroy CM . A review of neuroendocrine neoplasms of the larynx: U pdate on diagnosis and treatment. J Laryngol Otol 1998;112:827-34.

2. Barnes L. Paraganglioma of the larynx: A critical review of the literature. ORL J Otorhinolaryngol Relat Spec 1991;53:220-34.

3. Erickson D, Kudva Y C, Ebersold $M J$, et al. B enign Paragangliomas: Clinical presentation and treatment outcomes in 236 patients. J Clin Endocrinol M etab 2001;86:5210-16.

4. Bishop GB J r, U rist M M , el Gammal T, et al. Paragangliomas of the neck. A rch Surg 1992;127:1441-45.

5. Smolarz JR, Hanna EY, Williams MD, Kupferman ME. Paraganglioma of the endolarynx: A rare tumor in an uncommon location. Head N eck Oncol 2010;2:2.

6. Del Gaudio J M, Muller S. Diagnosis and treatment of supraglottic laryngeal paraganglioma: A case report. H ead N eck 2004 J an;26(1):94-98.

7. B atsakis J G, el-Naggar AK, L una M A. N euroendocrine tumors of larynx. A nn Otol Rhinol Laryngol 1992;101(8):710-14.

8. Ferlito A, B arnes L, W enig BM. Identification, classification, treatment, and prognosis of laryngeal paraganglioma. Review of the literature and eight new cases. A nn 0 tol R hinol Laryngol 1994; 103:525-36.

9. Persky MS, Setton A, Niimi Y, et al. Combined endovascular and surgical treatment of head and neck paragangliomas: A team approach. Head N eck 2002;24:423-31.

10. Tikkakaoski T, Luotonen J, L einonen $S$, et al. Preoperative embolization in the management of neck paragangliomas. L aryngoscope 1997;107:821-26.

11. Pierot $L, B$ oulin $A, C$ astings $L$, et al. Embolization by direct puncture of hypervascularised otorhinolaryngology tumours. A nn Otolaryngol Chir Cervicofac 1994;1111:403-09. 
12. Casasco A, Herbreteau D, Houdart E, et al. Devascularisation of craniofacial tumours by percutaneous tumour puncture. AJ NR A m J Neuroradiol 1994;15:1233-39.

13. Chloupka JC, M angla S, Huddle DC, et al. Evolving experience with direct puncture therapeutic embolization for adjunctive and palliative management of head and neck hypervascular neoplasms. Laryngoscope 1999;109:1864-72.

14. A bud DG, M ounayer C, B enndorf, et al. Intratumoral injection of cyanoacrylate glue in head and neck paragangliomas. AJ NR Am J Neuroradiol 2004;25:1457-62.

15. Sanders KW, Abreo F, Rivera E, Stucker FJ, Nathan CO. A diagnostic and therapeutic approach to paragangliomas of the larynx. A rch Otolaryngol Head N eck Surg 2001;127:565-69.

16. M yssiorek D, M adnani D, D elacure M D. The external approach for submucosal lesions of the larynx. Otolaryngol Head Neck Surg 2001;125:370-73.

17. Rubin J S, Silver CE. Surgical approach to submucosal lesions of the supraglottic Iarynx: The supero-lateral thyrotomy. J L aryngol Oto 1992;106:416-19.

18. M yssiorek $D$, Halaas $Y$, Silver $C$. Laryngeal and sinonasal paragangliomas. Otolaryngol Clin N orth A m 2001;34: 971-82.

19. Peterson KL, Fu Y S, Calcaterra T. Subglottic paraganglioma. Head Neck 1997;19:54-56.

20. Wasserman PG, Savargaonkar P. Paragangliomas: Classification, pathology, and differential diagnosis. O tolaryngol Clin North A m 2001;34:845-62.

21. Lustrin ES, Palestro C, V aheesan K. Radiographic evaluation and assessment of paragangliomas. Otolaryngol Clin $\mathrm{N}$ orth $\mathrm{A} \mathrm{m}$ 2001;34(5):881-906.

22. Dhakhwa R, T oran KC, Kafle S, Lakhey M. Paraganglioma of the larynx. J Pathol Nepal 2012;2:245-47.

23. $M$ artinez-M adrigal $F, B$ osq J, M icheau $C, N$ ivet $P$, L uboinski B. Paragangliomas of the head and neck. I mmunohistochemical analysis of 16 cases in comparison with neuro-endocrine carcinomas. Path Res Pract 1991;187:814-23.

24. Khademi B, Taghizadegan L, Gandomi B, Vasei M. Paraganglioma of the larynx: A case report. IJ M S 2004;29: 47-49.

25. Ferlito A, Silver CE, B radford CR, Rinaldo A. N euroendocrine neoplasms of the larynx: A n overview. Head Neck 2009 Dec;31(12):1634-46.

26. Jimenez C, Cote G, A rnold A, Gagel RF. Review: Should patients with apparently sporadic pheochromocytomas or paragangliomas be screened for hereditary syndromes? J Clin Endocrinol M etab 2006;91(8):2851-58.

27. Neumann HP, Pawlu C, Peczkowska M. Distinct clinical features of paraganglioma syndromes associated with SDHB and SD HD gene mutations. JA M A 2004;292(8):943-51.
28. Rubin A D, Cheng SS, B radford CR. L aryngeal paraganglioma in a patient with multiple head and neck paragangliomas. Otolaryngol Head Neck Surg 2005;132(3):520-22.

29. B lanchard CL, Saunders W H. Chemodectoma of the larynx; A case report. A M A A rch Otolaryngol 1955;61(4):472-74.

30. V ogl T, B runing R, Schedel H, Kang K, Grevers G, Hahn D, et al. Paragangliomas of the jugular bulb and carotid body: M R imaging with short sequences and Gd- DPTA enhancement. AJR 1989;153:583-87.

31. van Gils APG, van der Mey AGL, Hoogma RPLM, Sankuijl LA, M aaswinkel-M ooy PD, Falke THM, et al. M RI screening of kindred at risk of developing paragangliomas: Support for genomic imprinting in hereditary glomus tumours. $\mathrm{B} \mathrm{J}$ Cancer 1992;65:903-07.

32. V ogl TJ, J uergens M, B alzer JO, M ack M G, B ergman C, Grevers $G$, et al. G lomus tumors of the skull base: Combined use of $M R$ angiography and spin-echo imaging. Radiology 1994;192: 103-10.

33. van den $B$ erg $R$, Wasser $M N$, van Gils $A P$, van der $M$ ey $A G$, Hermans J, van B uchem M A. V ascularization of head and neck paragangliomas: Comparison of three angiographic techniques with digital subtraction angiography. A N R 2000;21:162-70.

34. Myssiorek D, Rinaldo A, Barnes L, Ferlito A. Laryngeal paraganglioma: A $n$ updated critical review. A cta Otolaryngol 2004;124(9):995-99.

35. Rao V, Raghavendra K S, Chavan P, Shenoy A M. V ocal cord paralysis following percutaneous embolization of a vagal paraganglioma. Int J Head Neck Surg 2011 Jan-A pr;2(1): 65-66.

36. George B, Casasco A, D effrennes D, Houdart E. Intratumoral embolization of intracranial and extracranial tumors: Technical note. N eurosurgery 1994;35:771-73.

37. Hinojar AG, Prieto JR, M unoz E, Hinojar A A. Relapsing paraganglioma of theinferior laryngeal paraganglion: Casereport and review of the literature. Head Neck 2002;24(1):95-102.

38. Ferlito A, M ilory CM, Wenig BM, et al. Laryngeal paraganglioma versus atypical carcinoid tumor. A nn Otol R hinol L aryngol 1995;104:78-83.

39. Kimura N, Chetty R, Capella C, et al. Extra-adrenal paraganglioma: Carotid body, jugulotympanic, vagal, laryngeal, aortico-pulmonary. In: DeLellis, Lloyd RV, Heitz PU, Eng C (Eds). Pathology and genetics. Tumors of endocrine organs. Lyon: IARC Press 2004;16.

\section{ABOUT THE AUTHOR}

\section{Sudhir M Naik}

Fellow, Department of Head and Neck Oncosurgery, Kidwai M emorial Institute of Oncology, B engaluru, K arnataka, India, Phone: 09916807109 e-mail: sud223@gmail.com 